\title{
Element sensor based on microplasma generators
}

\author{
Tomasz Matusiak \\ Faculty of Microsystem Electronics and Photonics, Wroclaw University of Science and Technology, \\ Wroclaw, Poland \\ Krzysztof Swiderski \\ Faculty of Chemistry, Wroclaw University of Science and Technology, Wroclaw, Poland \\ fan Macioszczyk \\ Faculty of Microsystem Electronics and Photonics, Wroclaw University of Science and Technology, \\ Wroclaw, Poland \\ Piotr Famroz and Pawel Pohl \\ Faculty of Chemistry, Wroclaw University of Science and Technology, Wroclaw, Poland, and \\ Leszek Golonka \\ Faculty of Microsystem Electronics and Photonics, Wroclaw University of Science and Technology, \\ Wroclaw, Poland
}

\begin{abstract}
Purpose - The purpose of this paper is to present a study on miniaturized instruments for analytical chemistry with a microplasma as the excitation source. Design/methodology/approach - The atmospheric pressure glow microdischarge could be ignited inside a ceramic structure between a solid anode and a liquid cathode. As a result of the cathode sputtering of the solution, it was possible to determine its chemical composition by analyzing the emission spectra of the discharge. Cathodes with microfluidic channels and two types of anodes were constructed. Both types were tested through experimentation. Impact of the electrodes geometry on the discharge was established. A cathode aperture of various sizes and anodes made from different materials were used.

Findings - The spectroscopic properties of the discharge and its usefulness in the analysis depended on the ceramic structure. The surface area of the cathode aperture and the flow rate of the solution influence on the detection limits (DLs) of $\mathrm{Zn}$ and Cd.

Originality/value - Constructed ceramic structures were able to excite elements and their laboratory-size systems. During the experiments, $\mathrm{Zn}$ and Cd were detected with DLs 0.024 and $0.053 \mathrm{mg} / \mathrm{L}$, respectively.
\end{abstract}

Keywords LTCC, Environmental sensors, Spectral analysis, Microplasma, Microchip, Optical emission spectroscopy

Paper type Research paper

\section{Introduction}

Increasing environmental pollution highlights challenges for new solutions for its protection by monitoring contamination in real time and directly in the place where it occurs. Usefulness of the present measuring systems satisfies the needs of laboratory facilities but due to their dimensions, it cannot be used in situ or their use may be difficult. Miniaturization of systems to the labon-chip level can serve as one of the solutions to this problem. Lab-on-chip systems are currently based on silicon, glass and ceramic substrates, using various microelectronic techniques for their processing. Especially, ceramic systems are suitable to be used in aggressive environments, for example, during plasma generation in various discharge gases. Atmospheric

The current issue and full text archive of this journal is available on Emerald Insight at: https://www.emerald.com/insight/0260-2288.htm

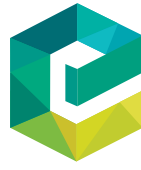

Sensor Review

40/4 (2020) 437-444

Emerald Publishing Limited [ISSN 0260-2288]

[DOI 10.1108/SR-11-2019-0259] pressure plasmas are efficient excitation sources for analytical optical emission spectrometry (OES). However, the most commonly used inductively coupled plasma (ICP) is a bulky excitation source that needs to be cooled and consumes a lot of energy and gas. Atmospheric pressure glow discharge (APGD) can be used instead of ICP due to lower operational and

(C) Tomasz Matusiak, Krzysztof Swiderski, Jan Macioszczyk, Piotr Jamroz, Pawel Pohl and Leszek Golonka. Published by Emerald Publishing Limited. This article is published under the Creative Commons Attribution (CC BY 4.0) licence. Anyone may reproduce, distribute, translate and create derivative works of this article (for both commercial and non-commercial purposes), subject to full attribution to the original publication and authors. The full terms of this licence may be seen at http://creativecommons.org/licences/by/4.0/legalcode

The authors wish to thank the National Science Centre of the Republic of Poland (under grant no. 2016/21/N/ST7/01618) and Wroclaw University of Science and Technology (statutory activity) for financial support.

Received 2 November 2019

Revised 13 February 2020

16 March 2020

Accepted 5 April 2020 
maintenance costs, but there is still the problem of a destructive impact of the discharge on metallic electrodes. One or both electrodes in APGD can be replaced by liquids, thereby enabling to stably generate the discharge in contact with them (Webb et al., 2005). The first of such discharge systems described in the literature by Cserfalvi and Mezei was electrolyte cathode atmospheric discharge (Cserfalvi and Mezei, 1994). APGD sustained and operated in contact with a flowing liquid electrode (FLE) has many advantages over other plasma-based excitation sources such as low power and gas consumption. Moreover, there is a significant reduction in the sample volume required for OES analysis (Cserfalvi and Mezei, 1994; Jamroz et al., 2017). The concept, which uses discharges generated in contact with liquids for elements sensing is presented in Figure 1.

The most important components in such system are: a supply and microfluidic introduction unit of samples to the microplasma based excitation source. During microplasma generation, emitted spectrum is characteristic for contaminants present in the liquid electrode. The microplasma can be driven by DC, AC, microwaves or by impulses (Bruggeman and Brandenburg, 2013). Applied power supplies mostly depend on construction of the microplasma generators. DC- and ACdriven discharges are typically used under atmospheric pressure for analytical chemistry purposes.

So far, various microsystems were proposed to sustain APGD generated in contact with analyzed sample solutions and determine in them different elements using this excitation source (Franzke and Miclea, 2006; Mitra et al., 2008; Jamroz et al., 2012; Schwartz et al., 2016). Miniaturization of these systems can significantly reduce costs of element analysis and amounts of samples required for this. Jamroz et al. (2017) presented a non-flowing and stationary setup, which required $50 \mu \mathrm{L}$ of a sample for one measurement.

This work presents a ceramic chip for sustaining microAPGD, which can be a part of a measuring shunt and does not require any special introduction unit of sample solutions to the microchip. This microAPGD can be implemented, for example, in real-time characterization of water pipes. So far, microAPGDs were generated in systems fabricated with the use of various micromechanical technologies (Franzke et al., 2003;

Figure 1 Components of the whole system based on the microplasma excitation source generated in contact with liquids for element analysis by $O E S$

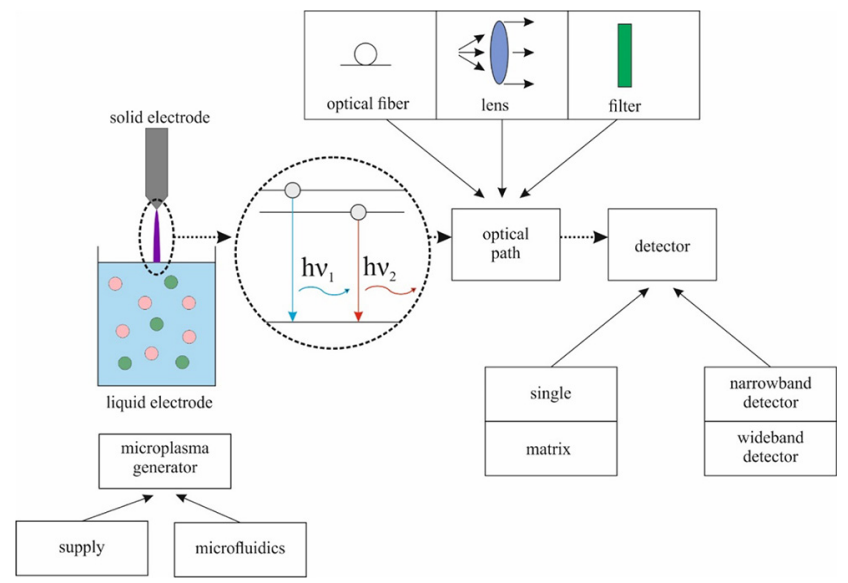

Gianchandani et al., 2009). In addition, Hopwood et al. (2000) and Bass et al. (2001) presented miniature ICP and capacitively coupled microplasma $(\mathrm{CC} \mu \mathrm{P})$, respectively, also fabricated in typical microelectronics technology. Materials used in low temperature co-fired ceramics (LTCC) technology work very well in extreme conditions of electric discharges, especially, under high temperatures and high voltages (Kita et al., 2015; Dabrowski et al., 2018). Examples of microplasma systems fabricated in LTCC technology are given in Table 1.

The aim of the present work was to:

- miniaturize a typical laboratory discharge setup,

- improve ceramic chips lately reported by Macioszczyk et al. (2016a, 2017a) and

- fabricate a ceramic structure for stable operation of $\mathrm{He}$ microAPGD between a solid anode and a flowing liquid cathode (FLC).

Macioszczyk et al. (2016a, 2017a) presented structures with a drop outlet of wastes and with completely evaporating solutions, respectively. Here, He microAPGD between a solid anode and a FLC solution inside a ceramic chip was developed and studied. Cathodes with microfluidic channels and two types of anodes were constructed. Both devices were tested as excitation sources prior to analytical OES and determination of traces of $\mathrm{Cd}$ and $\mathrm{Zn}$ in solutions. Although analytical performance of the proposed microAPGD excitation sources was fair, the microplasma sustained in developed ceramic chips degraded with time the surface of the LTCC substrates and electrodes.

\section{Materials and methods}

The concept of a microAPGD device proposed and developed in this paper is shown in Figure 2(a). Acidified solutions containing $\mathrm{Cd}$ and $\mathrm{Zn}$ were pumped into a microfluidic channel of a ceramic chip via a fluid inlet. Then, they filled the microfluidic channel until the inner cathode was touched and electrical connection was closed. The microplasma was sustained between the solid anode and the FLC formed. Due to sputtering of the solution surface, analytes were transported to the microAPGD column, where they were excited. Radiation emitted by microAPGD was focused onto the entrance slit of a spectrometer, using a collimating lens. The ceramic structure was placed inside a polymer housing to facilitate its operation and correct its position [Figure 2(b)].

A Du Pont GreenTape951 LTCC system (Du Pont, Wilmington, DE, USA) was used to fabricate the chip in LTCC technology. Successive layers of the cathode and both anodes are shown in Figure 3. All patterns were laser-cut (LPKF ProtoLaser U, Nd: YAG $355 \mathrm{~nm}$, LPKF Laser \& Electronics AG, Garbsen, Germany) on Du Pont 951PX green sheets (thickness of $254 \mu \mathrm{m}$ ).

The cathode consisted of eight layers. An external Au electrode (a Du Pont 5742 paste for an Au cofireable conductor), placed at the bottom of the Layer 8, was deposited by a $325 \mathrm{M}$ screen using a screen-printer (Aurel VS1520A, Aurel Automation S.P.A., Modigliana, Italy). The internal cathode was made of a Pt paste (a Du Pont 9141 Pt conductor) and connected to the external electrode by two vias filled with an Au paste (a Du Pont 5738 Au via fill). The microfluidic channel was located in Layers 3-6. The structure was covered by two additional layers (1-2) with a cathode aperture, where the plasma had contact with the solution, acting as the FLC. 
Table 1 Plasma chips fabricated in ceramic technology

\begin{tabular}{|c|c|c|}
\hline Description & Application & References \\
\hline APGD and a gas flowing through chamber & Technology presentation & Yamamoto et al. (2008) \\
\hline $\begin{array}{l}\text { Dielectric barrier discharge (DBD) and a gas flowing through chamber inside a } \\
\text { ceramic chip with open electrodes }\end{array}$ & Gas spectroscopy & Macioszczyk et al. (2016b) \\
\hline BDB with a gas flowing through chamber & Gas excitation & Vojak et al. (2001) \\
\hline RF microplasma-generating discharge & Technology presentation & Baker et al. (2006) \\
\hline DBD between buried electrodes in a ceramic chip & Selective treatment of cell cultures & Fischer et al. (2017) \\
\hline $\begin{array}{l}\text { APGD between a liquid cathode and a solid anode inside a ceramic chip; discharge } \\
\text { wastes are freely dropped out from a chip }\end{array}$ & Analytical atomic spectrometry & Macioszczyk et al. (2016a) \\
\hline $\begin{array}{l}\text { APGD between a liquid cathode and a solid anode inside a ceramic chip; the } \\
\text { cathode evaporates in a chamber }\end{array}$ & Analytical atomic spectrometry & Macioszczyk et al. (2017a) \\
\hline DBD between ceramic electrodes & Production of plasma activated water & Macioszczyk et al. (2017b) \\
\hline
\end{tabular}

Figure $2 \mathrm{~A}$ cross-section of a ceramic structure in which $\mathrm{He}$ microAPGD was sustained in contact with a flowing liquid cathode (a) and a view of a modular ceramic - polymeric device for OES analysis of liquids (b)

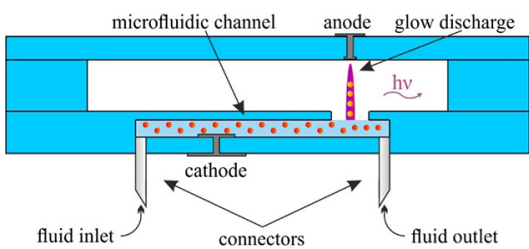

(a)

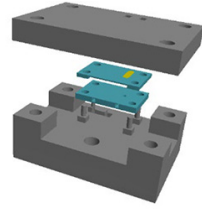

(b)
In the ceramic chip "Type 1" [Figure 4(a)], one of the anodes consisted of two layers with a screen-printed internal $\mathrm{Pt}$ electrode (Du Pont 9141), Au vias (Du Pont, 5738) and the external Au electrode (Du Pont 5742). In the second ceramic chip ["Type 2", Figure 4(b)], the electrode was made of a W wire placed inside the ceramic structure. Both ceramic structures were fabricated in the standard LTCC process. Only the lamination process was modified a little bit just to prevent microfluidic channels inside both chips from sagging. In this case, pressure was reduced from $20 \mathrm{MPa}$ to $5 \mathrm{MPa}$. After firing in standard conditions, ceramic structures were placed in the polymeric housing (Z-ABS material, Zortrax, Poland) that was made-up by fused deposition modeling (FDM) using a three-dimensional printer (M200, Zortrax, Poland). Dimensions of both ceramic chip structures were $21 \times 40 \times 2.6 \mathrm{~mm}$. As can be seen in Figure 3, $0.7 \mathrm{~mm}$ spacers were placed between the cathode and the anode. In the cathode, fluid connectors were glued.

Figure 3 Successive layers of ceramic cathode, spacers and anodes
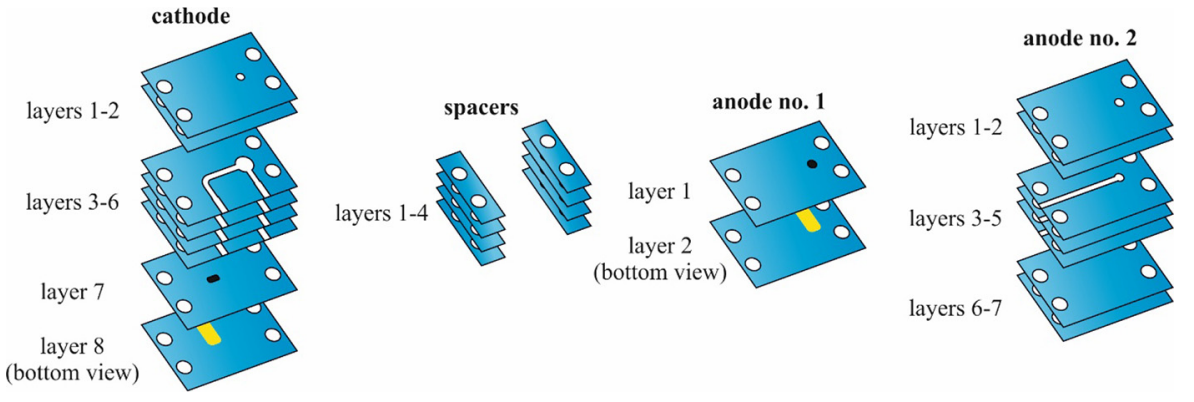

Figure 4 Ceramic chips with anodes with a screen-printed $\mathrm{Au}$ electrode ("Type 1") (a) and a solid W electrode ("Type 2") (b)

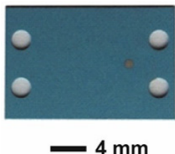

(a)

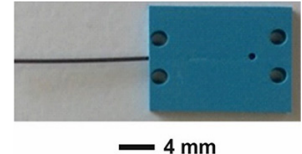

(b)

\section{Results}

The analytical performance of both modular ceramic polymeric structures, used for sustaining He microAPGD and analysis of solutions containing $\mathrm{Cd}$ and $\mathrm{Zn}$ by OES, was examined. The measurement setup (Figure 5) consisted of a

Figure 5 The measurement setup

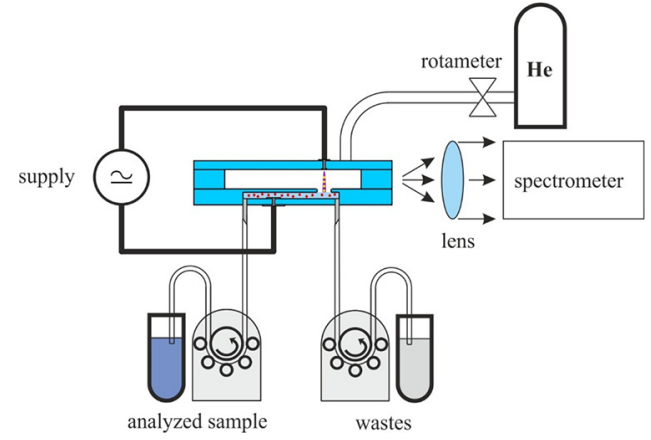


peristaltic pump (Reglo Ismatec ICC, Wertheim, Germany) with three independent pump channels, a pressurized container with $\mathrm{He}$ as working gas, power supplies for operation of highvoltage DC- or AC-driven microAPGDs (Dora Laboratory Equipment, Wroclaw, Poland) and a Shamrock SR500i imagining spectrometer (Andor, Oxford Instruments, Abingdon-on-Thames, GB) with a Newton DU-920-OE CCD detector. The spectrometer had two diffraction gratings: 1,800 lines/mm for the $200-400 \mathrm{~nm}$ spectral range and 1,200 lines/ $\mathrm{mm}$ for the $400-900 \mathrm{~nm}$ range. The analyzed liquid samples were $0.1 \mathrm{~mol} / \mathrm{L} \mathrm{HNO}_{3}$ solutions containing $\mathrm{Cd}(\mathrm{II})$ and $\mathrm{Zn}(\mathrm{II})$ ions at concentrations of 2, 5 and $10 \mathrm{mg} / \mathrm{L}$. Both DC- and ACdriven $\mathrm{He}$ microAPGDs were ignited and stably operated inside fabricated ceramic structures.

The ceramic chip "Type 1" for DC-driven He microAPGD operation is presented in Figure 6. In this case, the anode was connected into a circuit through a ballast resistor $(2 \mathrm{k} \Omega$, $250 \mathrm{~W})$. The DC-driven microAPGD device was run using the following parameters: a FLC solution flow rate of $0.5 \mathrm{~mL} / \mathrm{min}$, a He flow rate of $5 \mathrm{~L} / \mathrm{min}$, a discharge voltage of $1.7 \mathrm{kV}$ and a discharge current of $40 \mathrm{~mA}$ ( $68 \mathrm{~W}$ of power).

The plasma (Figure 6) was stable and homogeneous, but after $1 \mathrm{~h}$ of uninterrupted work, both electrodes started degrading and got destroyed. Relatively intensive Cd $(213.9 \mathrm{~nm})$ and $\mathrm{Zn}(228.8 \mathrm{~nm})$ atomic emission lines were observed in the spectrum of this He microAPGD. Additionally, $\mathrm{OH}, \mathrm{NO}, \mathrm{OH}$ and $\mathrm{N}_{2}$ molecular bands were identified (Table 2).

The device with the ceramic chip "Type 2" was used to sustain AC-driven microAPGD and was run without any significant deterioration of electrodes. Emission spectra of this microAPGD were acquired using the following operating parameters: a FLC flow rate of $1-4 \mathrm{~mL} / \mathrm{min}$, depending on

Figure 6 The DC-driven He microAPGD device

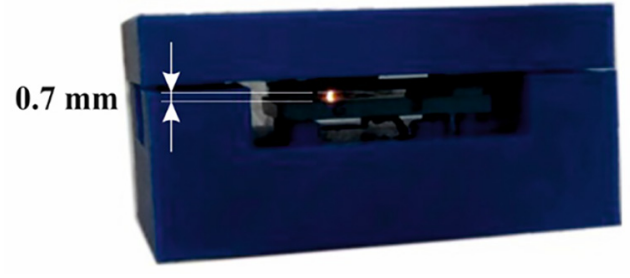

cathode aperture diameter, a He flow rate of $5 \mathrm{~L} / \mathrm{min}$, a peakto-peak voltage of $7.5 \mathrm{kV}$, a mean current of $4 \mathrm{~mA}$ and a frequency of carrier wave of $1.37 \mathrm{kHz}$. The current value confirmed that it was the glow discharge (Roth et al., 2005). The voltage waveform during the AC-driven discharge are presented in Figure 7.

As before, intensive atomic emission lines of $\mathrm{Zn}$ and $\mathrm{Cd}$ were identified at $213.9 \mathrm{~nm}$ and $228.8 \mathrm{~nm}$, respectively (Figure 8). Intensities of band heads of other molecular species identified in these spectra are given in Table 2. As AC-driven microAPGD sustained in the ceramic chip "type 2 " was more stable than DC-driven microdischarge sustained in the ceramic chip "type 1", it was used in all subsequent experiments.

Detection limits (DLs) of $\mathrm{Cd}$ and $\mathrm{Zn}$ achievable with DCand AC-driven He microAPGD were assessed on the following equation (Armbruster and Pry, 2008; Belter et al., 2014):

$$
\mathrm{DL}=\frac{3 \sigma}{a}
$$

where $\sigma$ is the standard deviation of the repeatedly measured intensity of the background for a blank solution $(0.1 \mathrm{~mol} / \mathrm{L}$ $\mathrm{HNO}_{3}$ ) and $a$ is the slope of the calibration curve (sensitivity) with the upper linearity range at $10 \mathrm{mg} / \mathrm{L}$ (the highest concentrated solution measured in this work). DLs of Cd and $\mathrm{Zn}$ achievable using the DC-driven microdischarge were determined to be $0.082 \mathrm{mg} / \mathrm{L}$ and $0.24 \mathrm{mg} / \mathrm{L}$, respectively.

Figure 7 Voltage waveform of AC-driven discharge by Dora supply

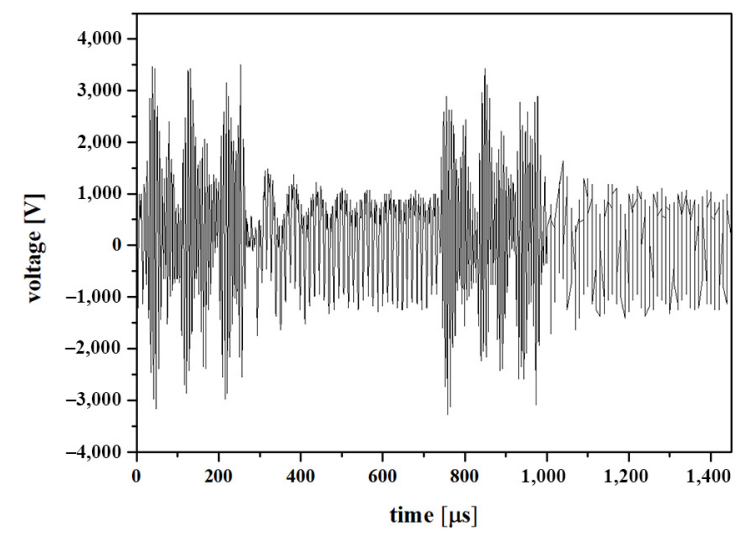

Table 2 Intensities of atomic lines and molecular bandheads

\begin{tabular}{|c|c|c|c|}
\hline \multirow[b]{2}{*}{ Wavelength [nm] } & \multirow[b]{2}{*}{ Atom/molecule transitions } & \multicolumn{2}{|c|}{ Intensity [a. u.] } \\
\hline & & AC-driven microAPGD & DC-driven microAPGD \\
\hline 213.9 & Zn I & $2.70 \times 10^{3}$ & $1.70 \times 10^{3}$ \\
\hline 228.8 & $\mathrm{Cdl}$ & $2.22 \times 10^{3}$ & $5.44 \times 10^{3}$ \\
\hline 247.9 & NO $(A-X)$ & $4.20 \times 10^{3}$ & $7.36 \times 10^{3}$ \\
\hline 282.9 & $\mathrm{OH}(\mathrm{A}-\mathrm{X})$ & $7.07 \times 10^{3}$ & $4.21 \times 10^{3}$ \\
\hline 308.9 & $\mathrm{OH}(\mathrm{A}-\mathrm{X})$ & $6.43 \times 10^{3}$ & $5.70 \times 10^{4}$ \\
\hline 337.2 & $\mathrm{~N}_{2}(\mathrm{C}-\mathrm{B})$ & $1.15 \times 10^{5}$ & $5.40 \times 10^{3}$ \\
\hline 357.7 & $\mathrm{~N}_{2}(\mathrm{C}-\mathrm{B})$ & $5.20 \times 10^{4}$ & $4.70 \times 10^{3}$ \\
\hline 375.5 & $\mathrm{~N}_{2}(\mathrm{C}-\mathrm{B})$ & $1.06 \times 10^{4}$ & $3.60 \times 10^{3}$ \\
\hline 380.2 & $\mathrm{~N}_{2}(\mathrm{C}-\mathrm{B})$ & $9.38 \times 10^{3}$ & $4.50 \times 10^{3}$ \\
\hline 589.0 & $\mathrm{NaI}$ & $9.98 \times 10^{3}$ & not detected \\
\hline
\end{tabular}


Figure 8 Emission spectra of AC-driven He microAPGD sustained in the ceramic structure "Type 2 anode" - the effect of the cathode aperture diameter. The concentration of $\mathrm{Cd}$ and $\mathrm{Zn}-2 \mathrm{mg} / \mathrm{L}$

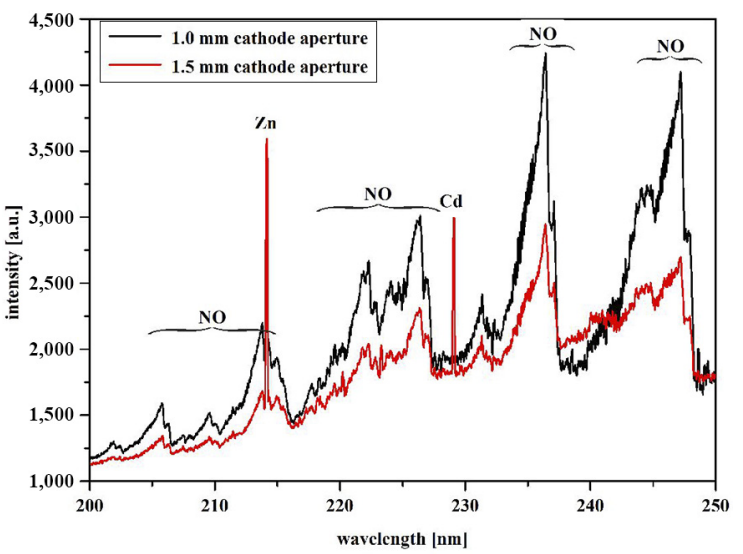

Nevertheless, due to rapid degradation of anodes in ceramic chips "Type 1" and "Type 2"), the DC-driven He microAPGD was not further investigated. In this case, the lifespan of mentioned above ceramic chips, used for DC-driven $\mathrm{He}$ microAPGD operation, was $1 \mathrm{~h}$ and $2 \mathrm{~h}$, respectively. Therefore, AC-driven He microAPGD was used in further experiments. In this case, DLsof $\mathrm{Cd}$ and $\mathrm{Zn}$ were established to be dependent on the FLC solution flow rate (from 1 to $4 \mathrm{~mL}$ / $\mathrm{min})$ and the cathode aperture diameter $(1.0 \mathrm{~mm}$ and $1.5 \mathrm{~mm})$. Respective results are given in Table 3.

As Table 3 demonstrates, different values of DLs of Cd and $\mathrm{Zn}$ were obtained for each cathode aperture and FLC solution flow rate. The lowest DLs of $\mathrm{Cd}(0.053 \mathrm{mg} / \mathrm{L})$ and $\mathrm{Zn}$ $(0.14 \mathrm{mg} / \mathrm{L})$ were established when using a cathode aperture diameter of $1.5 \mathrm{~mm}$ and a FLC solution flow rate of $1 \mathrm{~mL} / \mathrm{min}$. In these conditions, background intensity fluctuation in vicinity of atomic emission lines of $\mathrm{Cd}$ and $\mathrm{Zn}$ for the measured blank solution, expressed as $\sigma$, was the lowest and equaled 39.2 and 126 , respectively.

Intensity responses for three concentrations are presented in Figure 9.

\section{Discussion}

DC-driven He microAPGD sustained and operated in the ceramic chip "Type 1" was unstable; the lifespan of the mentioned chip structure was relatively short (about $1 \mathrm{~h}$ ). Surfaces of both electrodes (anode and cathode, Figure 10)
Figure 9 Intensity responses of for three concentrations of $\mathrm{Cd}$ and $\mathrm{Zn}$

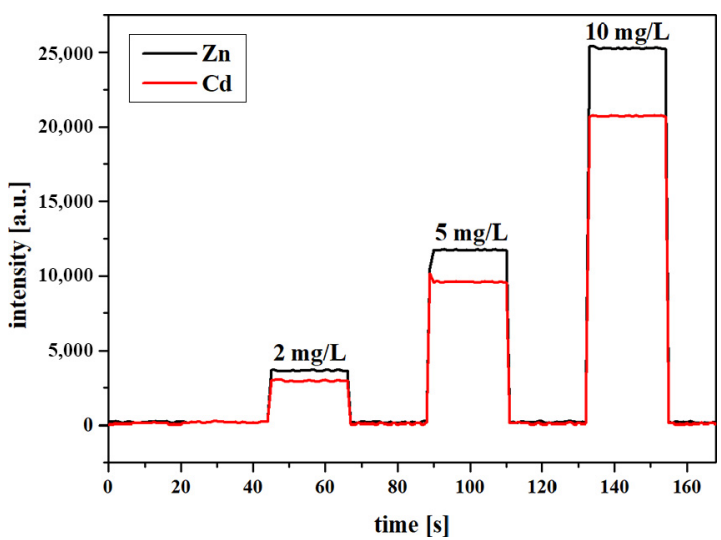

Figure 10 Electrodes degraded in ceramic chips used for sustaining DC-driven microAPGD

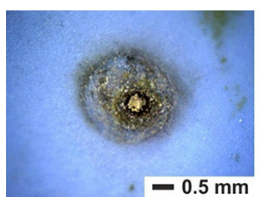

(a)

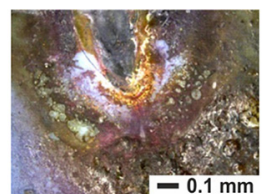

(b)

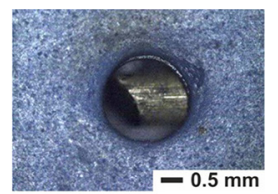

(c)
Notes: (a) Anode in chip "type 1" and; (b) cathode in chip "type 1 ", and non-degraded AC-driven microAPGD; (c) anode in chip "type 2" after use with AC-driven microAPGD with any damage

included in this chip were imaged with the aid of a Leica DM4000 M LED microscope (Leica Microsystems, Wetzlar, Germany).

Pt metallization of the anode (thickness $10 \mu \mathrm{m}$ ) in the ceramic chip "Type 1" was almost completely etched by the plasma up to the via. On the bottom of the cathode, some cracks were observed in the ceramic, in addition to a partially melted glass phase and some metallic contamination on the surface. Screen-printed metallization was no longer present in these conditions. To reduce the impact of the constant electrical field on the anode and the cathode in the ceramic chip "Type 1", the power supply was changed from DC to AC. In addition, the anode in the device was replaced with a W wire (the ceramic chip "Type 2"). Hence, the W anode had a higher melting point and was more reliable than the thin Pt electrode.

Table 3 Comparison of DLs of $\mathrm{cd}$ and Zn obtained for AC-driven microAPGD operated in the ceramic chip "Type 2" under different experimental conditions related to the $\mathrm{FLC}$ solution flow rate and the cathode aperture diameter

DLs [mg/L]

$\mathrm{Cd}$
Cathode aperture diameter $[\mathrm{mm}]$

1.0

$1.5-1.0$

$0.053 \quad 0.42$

$0.16-0.30$

$0.097-0.25$

0.053
$\mathrm{Zn}$

\begin{tabular}{ll}
.0 & 1.5 \\
\hline .42 & 0.14 \\
.30 & 0.25 \\
.25 & 0.26 \\
16 & 0.22
\end{tabular}


Table 4 Comparison of DLs of $\mathrm{cd}$ and Zn reported in literature with those obtained in the present study for DC-driven microAPGD (sustained in the ceramic chip "Type 1") and AC-driven microAPGD (sustained in the ceramic chip "Type 2")

\begin{tabular}{lcr}
\hline Source & Cd & DLs [mg/L] \\
\hline Cserfalvi and Mezei (1994) & 0.10 & 0.10 \\
Jamróz et al. (2012) & 0.20 & 0.14 \\
Schwartz et al. (2016) & 0.053 & 0.20 \\
Kim et al. (2000) & - & 0.60 \\
Jamróz et al. (2012) & 0.05 & 0.14 \\
Macioszczyk et al. (2016a) & 0.082 & 0.20 \\
This work (ceramic chip "Type 1" for DC-driven microAPGD) & 0.053 & 0.024 \\
This work (ceramic chip "Type 2"for AC-driven microAPGD) & 0.14 \\
\hline
\end{tabular}

Certainly, this construction solved the problem of the short lifespan of the ceramic structure. In addition, microAPGD was more stable.

Molecular bands of the $\mathrm{OH}(\mathrm{A}-\mathrm{X})$ system were observed in emission spectra of both DC- and AC-driven microAPGDs, which resulted from dissociation of water vapor. Based on these $\mathrm{OH}$ molecular emission spectra, it was possible to determine rotational temperature $\left(\mathrm{T}_{\mathrm{rot}}\right)$ of the plasma (Jamroz et al., 2012). Lifbase software (version: 2.1, SRI International, Menlo Park, CA, USA) was used to assess this value. In this case, the empirical $\mathrm{OH}$ molecular emission spectrum was compared with those simulated at different $\mathrm{T}_{\text {rot }}$ values. In case of $\mathrm{AD}$ driven $\mathrm{He}$ microAPGD, it was established that the highest correlation $(\mathrm{R}=0.93)$ between modeled and measured spectra was for $\mathrm{T}_{\text {rot }}=3,000 \mathrm{~K}$. For the $\mathrm{DC}$-driven discharge, the $\mathrm{T}_{\text {rot }}$ value was established to be $4,500 \mathrm{~K}$ with the correlation coefficient of 0.91 . Intensive emission from $\mathrm{N}_{2}$ molecules was likely related to diffusion of $\mathrm{N}_{2}$ from the surrounding air into the microAPGD column.

When a smaller cathode aperture $(1.0 \mathrm{~mm})$ was used, higher power density was achieved, hence, higher amounts of analytes were likely sputtered into the microAPGD phase in these conditions. As a result, it was possible to introduce higher amounts of solutions at increased flow rates, i.e. up to $4 \mathrm{~mL} /$ min. Therefore, intensities of atomic emission lines of $\mathrm{Cd}$ and $\mathrm{Zn}$ were higher and subsequently higher slopes of calibration curves were established, giving rise to lower DLs of $\mathrm{Cd}$ and $\mathrm{Zn}$. When a higher cathode aperture $(1.5 \mathrm{~mm})$ was used, available power density was lower. In these conditions, the system was cooled at higher FLC solution flow rates due to higher amounts of water vapor in the microAPGD phase. As a result, the highest intensities of atomic emission lines of $\mathrm{Cd}$ and $\mathrm{Zn}$ were obtained at the lowest flow rate, i.e. $1 \mathrm{~mL} / \mathrm{min}$. Detectability of $\mathrm{Zn}$ was weaker than this for $\mathrm{Cd}$ because the analytical line of this element interfered with the NO molecular band in this spectral range. Hence, the standard deviation of the background in vicinity of the $\mathrm{Zn}$ atomic emission line was deteriorated. Its higher values obtained in these conditions resulted in worsening the $\mathrm{DL}$ of $\mathrm{Zn}$. It was not the case of $\mathrm{Cd}$, which atomic emission line was not interfered by any molecular spectra. Therefore, it was concluded that the ceramic chip "Type 2" with both apertures could be used for measurements of this element. DLs of $\mathrm{Cd}$ and $\mathrm{Zn}$ obtained in this study with the developed AC-driven $\mathrm{He}$ microAPGD system are compared with those reported in other works in Table 4.

\section{Conclusion}

The present work brings a completely new miniature device for determination of $\mathrm{Cd}$ and $\mathrm{Zn}$ in solutions by analytical OES. The device was based on the $\mathrm{He}$ microAPGD excitation source, microAPGD was ignited between the solid anode and the FLC solution. Anodes and the microfluidic compartment within the cathode were entirely fabricated using LTCC technology. Developed ceramic structures were placed inside a polymeric housing made in three-dimensional printing technology. The AC-driven microAPGD system appeared to have better performance than the DC-driven system; it uninterruptedly run for a few hours during OES measurements. Under optimal experimental conditions, DLs of $\mathrm{Cd}$ and $\mathrm{Zn}$ obtained with AC-driven microAPGD were 0.053 and $0.14 \mathrm{mg} / \mathrm{L}$, respectively, which was comparable or better than DLs reported by other researchers for similar microplasma excitation sources (Table 4). DLs of elements were, in general, better than these reported in the earlier work (Macioszczyk et al., 2016a). During all experiments, cathodes within ceramic chips used for sustaining the AC-driven discharge demonstrated very good reliability. Screen-printed anodes (thickness $10 \mu \mathrm{m}$ ) were etched by the microplasma, but the solid W anode (50 $\mu \mathrm{m}$ wire diameter) exhibited better durability (W has higher melting point than $\mathrm{Pt}$ ). A higher $\mathrm{T}_{\text {rot }}$ value for the DC-driven discharge as compared to this for the AC-driven discharge was likely the reason why the cathode and the anode in the ceramic chip "Type 1", used for operation of the DC-driven discharge, had poorer durability Figure 10 (a) and 10(b).

\section{References}

Armbruster, D.A. and Pry, T. (2008), "Limit of blank, limit of detection and limit of quantitation", The Clinical biochemist, Reviews, available at: www.ncbi.nlm.nih.gov/ pubmed/18852857\%0Awww.pubmedcentral.nih.gov/articlerender. fcgi?artid=PMC2556583, pp. S49-S52.

Baker, A., Randall, C., Stewart, R., Fantazier, R. and Wise, F. (2006), "Fabrication of a multilayered low-temperature cofired ceramic micro-plasma-generating device", International fournal of Applied Ceramic Technology, Vol. 3 No. 6, pp. 413-418, doi: 10.1111/j.1744-7402.2006.02104. $\mathrm{x}$.

Bass, A., Chevalier, C. and Blades, M.W. (2001), “A capacitively coupled microplasma $(\mathrm{CC} \mu \mathrm{P})$ formed in a channel in a quartz 
wafer", Fournal of Analytical Atomic Spectrometry, Vol. 16 No. 9, pp. 919-921, doi: 10.1039/b103507j.

Belter, M., Sajnóg, A. and Barałkiewicz, D. (2014), "Over a century of detection and quantification capabilities in analytical chemistry - Historical overview and trends", Talanta, Vol. 129, pp. 606-616, doi: 10.1016/j. talanta.2014.05.018.

Bruggeman, P. and Brandenburg, R. (2013), “Atmospheric pressure discharge filaments and microplasmas: physics, chemistry and diagnostics", Fournal of Physics D: Applied Physics, Vol. 46 No. 46, doi: 10.1088/0022-3727/46/46/ 464001.

Cserfalvi, T. and Mezei, P. (1994), "Direct solution analysis by glow discharge: electrolyte-cathode discharge spectrometry", Fournal of Analytical Atomic Spectrometry, Vol. 9 No. 3, pp. 345-349, doi: 10.1039/ja9940900345.

Dabrowski, A., Rydygier, R., Czok, M. and Golonka, L. (2018), "High voltage applications of low temperature cofired ceramics", Microelectronics International, Vol. 35 No. 3, pp. 146-152, doi: 10.1108/MI-12-2017-0070.

Fischer, M., Stubenrauch, M., Naber, A.M., Gutzeit, N., Klett, M., Singh, S., Schober, A., Holger Witte, H. and Müller, J. (2017), "Keramische Mikro-Plasmaquelle für die selektive behandlung von zellkulturen LTCC-Based micro plasma source for the selective treatment of cell cultures kurzfassung einleitung systemdesign", Proceedings MikroSystemTechnik Kongress 2017, 23-25. Oktober 2017, München, pp. 762-765.

Franzke, J. and Miclea, M. (2006), "Sample analysis with miniaturized plasmas", Applied Spectroscopy, Vol. 60 No. 3, pp. 80A-90A, doi: 10.1366/000370206776342689.

Franzke, J., Kunze, K., Micleaa, M. and Niemax, K. (2003), "Microplasmas for analytical spectrometry", Fournal of Analytical Atomic Spectrometry, Vol. 18 No. 7, pp. 802-807, doi: 10.1039/b300193h.

Gianchandani, Y.B., Wright, S.A., Eun, C.K., Wilson, C.G. and Mitra, B. (2009), "Exploring microdischarges for portable sensing applications", Analytical and Bioanalytical Chemistry, Vol. 395 No. 3, pp. 559-575, doi: 10.1007/ s00216-009-3011-6.

Hopwood, J., Minayeva, O. and Yin, Y. (2000), "Fabrication and characterization of a micromachined 5 $\mathrm{mm}$ inductively coupled plasma generator", Fournal of Vacuum Science \& Technology B: Microelectronics and Nanometer Structures, Vol. 18 No. 5, pp. 2446-2451, doi: $10.1116 / 1.1288945$.

Jamroz, P., Greda, K. and Pohl, P. (2012), "Development of direct-current, atmospheric-pressure, glow discharges generated in contact with flowing electrolyte solutions for elemental analysis by optical emission spectrometry", TrAC Trends in Analytical Chemistry, Vol. 41 No. 12, pp. 105-121, available at: www.sciencedirect.com/science/ article/pii/S0165993612002701

Jamróz, P., Pohl, P. and Zyrnicki, W. (2012), “An analytical performance of atmospheric pressure glow discharge generated in contact with flowing small size liquid cathode", Fournal of Analytical Atomic Spectrometry, Vol. 27 No. 6, pp. 1032-1037, doi: 10.1039/c2ja30017f.

Jamroz, P., Greda, K., Dzimitrowicz, A., Swiderski, K. and Pohl, P. (2017), "Sensitive determination of cd in Small-
Volume samples by miniaturized liquid drop anode atmospheric pressure glow discharge optical emission spectrometry", Analytical Chemistry, Vol. 89 No. 11, pp. 5729-5733, doi: 10.1021/acs.analchem.7b01198.

Kim, H.J., Lee, J.H., Kim, M.Y., Cserfalvi, T. and Mezei, P. (2000), "Development of open-air type electrolyte-ascathode glow discharge-atomic emission spectrometry for determination of trace metals in water", Spectrochimica Acta Part B: Atomic Spectroscopy, Vol. 55 No. 7, pp. 823-831, doi: 10.1016/S0584-8547(00)00209-3.

Kita, J., Engelbrecht, A., Schubert, F., Groß, A., Rettig, F. and Moos, R. (2015), "Some practical points to consider with respect to thermal conductivity and electrical resistivity of ceramic substrates for high-temperature gas sensors", Sensors and Actuators B: Chemical, Vol. 213, pp. 541-546, doi: 10.1016/j.snb.2015.01.041.

Macioszczyk, J., Lenartowicz, M., Malecha, K. and Golonka, L. (2016a), "Design and fabrication of ceramic microsystem utilizing glow discharge for analysis of liquid mixtures", IMAPS/ACerS 12th International Conference and Exhibition on Ceramic Interconnect and Ceramic Microsystems Technologies, CICMT 2016, pp. 80-84.

Macioszczyk, J., Malecha, K. and Golonka, L.J. (2016b), "The LTCC device for miniature plasma generators characterization", Microelectronics International, Vol. 33 No. 3, pp. 149-154, doi: 10.1108/MI-03-2016-0021.

Macioszczyk, J., Matusiak, T., Jamroz, P. and Golonka, L. (2017a), "Ceramic atmospheric pressure micro glow discharge device with evaporating liquid flowing cathode for analytical purposes", Proceedings of the International Spring Seminar on Electronics Technology, doi: 10.1109/ ISSE.2017.8000981.

Macioszczyk, J., Olszewski, P., Jamroz, P. and Golonka, L. (2017b), "Portable reactor with LTCC electrodes for production of plasma activated water", EMPC 2017 - 21st European Microelectronics and Packaging Conference and Exhibition, 2018-fanuary, pp. 1-4, doi: 10.23919/ EMPC.2017.8346922.

Mitra, B., Levey, B. and Gianchandani, Y.B. (2008), "Hybrid arc/glow microdischarges at atmospheric pressure and their use in portable systems for liquid and gas sensing", IEEE Transactions on Plasma Science, Vol. 36 No. 4, pp. 1913-1924, doi: 10.1109/TPS.2008.927135.

Roth, J.R., Rahel, J., Dai, X. and Sherman, D.M. (2005), "The physics and phenomenology of one atmosphere uniform glow discharge plasma (OAUGDP ${ }^{\mathrm{TM}}$ ) reactors for surface treatment applications", fournal of Physics D: Applied Physics, Vol. 38 No. 4, pp. 555-567, doi: 10.1088/0022-3727/38/4/ 007.

Schwartz, A.J., Ray, S.J., Chan, G.C.Y. and Hieftje, G.M. (2016), "Spatially resolved measurements to improve analytical performance of solution-cathode glow discharge optical-emission spectrometry", Spectrochimica Acta Part B: Atomic Spectroscopy, Vol. 125, pp. 168-176, doi: 10.1016/j. sab.2016.10.004.

Vojak, B.A., Park, S.-J., Wagner, C.J. and Eden, J.G. (2001), "Multistage, monolithic ceramic microdischarge device having an active length of $\sim 0.27 \mathrm{~mm}$ ", Applied Physics Letters, Vol. 78 No. 10, pp. 1340-1342, doi: 10.1063/1.1352042. 
Webb, M.R., Andrade, F.J., Gamez, G. and Crindle, R.M. (2005), "Spectroscopic and electrical studies of a solutioncathode glow discharge", Fournal of Analytical Atomic Spectrometry, Vol. 20 No. 11, pp. 1218-1225, doi: 10.1039/ b503961d.

Yamamoto, R.K., Gongora-Rubio, M.R., Pessoa, R.S., Cunha, M.R. and Maciel, H.S. (2008), "Mixed LTCC and LTTT technology for microplasma generator fabrication", 4th IMAPS/ACerS International Conference and Exhibition on Ceramic Interconnect and Ceramic Microsystems Technologies 2008, CICMT 2008, (April), pp. 612-618, doi: 10.4071/ 1551-4897-6.2.101.

\section{Corresponding author}

Tomasz Matusiak can be contacted at: tomasz.matusiak@, pwr.edu.pl

For instructions on how to order reprints of this article, please visit our website:

www.emeraldgrouppublishing.com/licensing/reprints.htm

Or contact us for further details: permissions@emeraldinsight.com bn 